\title{
NÚCLEO DE PESQUISA E OLIMPÍADAS COMO ESTRATÉGIA PARA EDUCAÇÃO EM CIÊNCIAS NOS CENTROS EDUCA MAIS DO MARANHÃO
}

\author{
Marcos Eduardo Miranda Santos ${ }^{\text {a*}}$, Thiago Gomes Alves ${ }^{\mathrm{a}}$, Sidney Fernandes Mendonça ${ }^{\mathrm{a}}$, Raquel Melo \\ de Assis ${ }^{\mathrm{a}}$ \\ ${ }^{a}$ Supervisão dos Centros de Educação em Tempo Integral. Secretaria de Estado da Educação. Rua das Figueiras, 101 - \\ Jardim Sao Francisco, São Luís, MA, Brasil. \\ *E-mail para correspondência: markoseduardo2008@hotmail.com
}

\section{Palavras-chave: \\ Educação Científica; \\ Metodologia de êxito; \\ Protagonismo \\ estudantil.}

\section{RESUMO}

Os Centros Educa Mais constituem uma das redes de ensino público em tempo integral do estado do Maranhão. Este relato detalha o processo de implantação do Núcleo de Pesquisa e Olimpíadas (NPO) nos Centros Educa Mais e os resultados obtidos, pelos alunos e professores, no que diz respeito à participação e premiação em olimpíadas e eventos científicos. De modo geral, foi constatado que o número de participação efetiva e premiação dos Centros aumentaram de forma expressiva em relação aos anos anteriores, após a implantação do Núcleo.

\section{ABSTRACT}

The Educa Mais Centers constitute one of the full-time public education

\section{Keywords:}

Science Education;

Methodology of success; Student Protagonism. networks in the state of Maranhão. This report details the implementation process of the Center for Research and Olympics (NPO) in the Educa Mais Centers and the results obtained, by students and teachers, concerning participation and awards in Olympics and scientific events. In general, it was found that the number of effective participation and awards in the Centers increased significantly in previous years, after the implementation of the Center. 


\section{INTRODUÇÃO}

Um dos fins básicos da Educação Científica é garantir aos estudantes uma compreensão adequada da natureza da ciência (PETRUCCI, URE, 2001). Tal prerrogativa é essencial para o letramento científico através da pesquisa. Além disso, a alfabetização científica representa uma possibilidade de corrigir práticas conteudistas no ensino de Ciências (CHASSOT, 2003), dando mais visibilidade ao protagonismo estudantil.

A pesquisa científica em instituições de ensino que trabalham a Ciência no âmbito da extensão e inovação é uma área que tem se desenvolvido bastante no Brasil nos últimos anos (FÓRUM DE REFLEXÃO UNIVERSITÁRIA, 2002). Entretanto, no contexto do Ensino Básico, ainda há problemas que necessitam de atenção especial.

Uma metodologia que tem sido adotada pelas escolas é o incentivo para seus estudantes participarem de Olimpíadas do Conhecimento, e mais recentemente, de eventos científicos, que até certo tempo atrás, tinham como público-alvo apenas o público universitário. As Olimpíadas do Conhecimento, além de estimularem o desenvolvimento de habilidades científicas e intelectuais, requerem persistência, motivação e curiosidade, fatores determinantes para o desenvolvimento do aluno quanto indivíduo (PEREIRA; MAREGA JR, 2009).

No Estado do Maranhão, como parte da Macropolítica Escola Digna, instituída por meio da Lei $\mathrm{N}^{\circ} 10.995$ de 11 de março de 2019, com objetivo de consolidar ações educativas objetivando a execução de políticas educacionais condizentes às orientações do Plano Nacional de Educação (MARANHÃO, 2019), integra-se, com relevância e expressividade, a implantação e sustentabilidade das Escolas em Tempo Integral.

A Implantação do Ensino Integral no Estado está em consonância com a Meta 6 do Plano Nacional de Educação (PNE) (BRASIL, 2014), que prioriza oferecer, até 2024, educação em tempo integral em, no mínimo, 50\% (cinquenta por cento) das escolas públicas, de forma a atender, pelo menos, $25 \%$ (vinte e cinco por cento) dos (as) alunos(as) da educação básica e também está alinhada ao Plano Estadual de Educação (MARANHÃO, 2016) que estabelece, que até 2020, o Estado deveria oferecer Educação Integral em jornada ampliada em, no mínimo, $10 \%$ das escolas públicas de modo a atender 9,8\% dos alunos da Educação Básica.

As Escolas em tempo integral têm apresentado importantes resultados qualitativos e quantitativos, a partir de um novo modelo de escola pública que visa o desenvolvimento dos estudantes em todas as suas dimensões. Esse novo modelo de escola pública visa o desenvolvimento dos estudantes em todas as suas dimensões - intelectual, social, cultural, física e emocional -, por meio de ações integradas e em tempo integral, envolvendo atores que

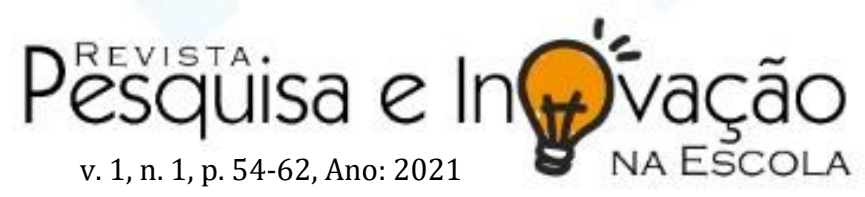


influenciam diretamente a formação plena dos estudantes: família, educadores, gestores e comunidades locais (MARANHÃO, 2021, p. 55-56).

Uma das redes de ensino em tempo integral em atividade no Maranhão são os Centros Educa Mais, vinculada à Secretaria Adjunta de Educação Profissional e Integral (SAEPI), da Secretaria de Estado da Educação (SEDUC). Esta rede atualmente conta com 55 escolas espalhadas em todo o estado que ofertam educação em tempo integral para cerca de 17 mil estudantes. Nos Centros Educa Mais, é promovida uma educação voltada para o exercício da cidadania e do protagonismo juvenil, o estudante fortalece a construção dos seus projetos de vida e visão de futuro (MARANHÃO, 2021, p. 68).

Dentre os diferenciais desta rede, cita-se: modelo instigante e inovador; oferta de disciplinas eletivas definidas a partir de uma seleção de temas escolhidos por estudantes e professores; valorização das experiências dos estudantes, inovação no processo de ensino e aprendizagem, diminuição no abandono escolar, promoção da iniciação científica e bons resultados nos indicadores educacionais (MARANHÃO, 2021).

Considerando a tendência de viabilizar a pesquisa científica na Educação Básica, estendê-la e popularizá-la, foi implantado nos Centros Educa Mais, o Núcleo de Pesquisa e Olimpíadas (NPO), como uma estratégia educacional promissora de nível estadual, que atua para promover a integração, a troca de conhecimentos, a formação de valores e ideias inovadoras entre professores e estudantes da rede Educa Mais e de instituições das localidades adjacentes de forma interinstitucional, além de despertar nos estudantes e professores uma cultura investigativa para ressignificação do ensino e aprendizagem. Neste relato de experiência, será detalhado o processo de implantação do NPO nos Centros Educa Mais do Maranhão e os resultados obtidos, no que diz respeito à participação em olimpíadas e eventos científicos, desde sua implantação em 5 de fevereiro de 2021, até o presente momento, de modo a incentivar outras redes de ensino a adotarem tal metodologia.

\section{METODOLOGIA}

O Núcleo de Pesquisa e Olimpíadas (NPO) tem como função maior coordenar as ações de pesquisa, integradas ao ensino, de modo a estabelecer processos de intercâmbio com instituições e empresas, com a missão de assegurar condições para o fortalecimento da pesquisa e da produção do conhecimento com qualidade e relevância para o desenvolvimento da Ciência e Tecnologia. Assim, desenvolve atividades que envolvem ensinar, aprender, pesquisar e 
divulgar a cultura, o pensamento, a arte, o saber, a ciência e a tecnologia, contribuindo para o desenvolvimento da pesquisa científica nos Centros Educa Mais.

No âmbito da Secretaria de Estado da Educação (SEDUC), por intermédio da Supervisão dos Centros de Educação em Tempo Integral (SUPCETI), o Núcleo de Pesquisa e Olimpíadas (NPO) vincula-se à Coordenação de Inovação, com anuência das Unidades Regionais de Educação (URE). Nas escolas, as atividades de pesquisa relacionadas ao Núcleo são orientadas por professores coordenadores de cada um dos Centros, que atuam na implementação de programas de pesquisa e direcionamento dos professores nos processos de submissão de projetos de pesquisa a órgãos de fomento estaduais e nacionais e, incentivo à participação dos estudantes nas principais olimpíadas do conhecimento da Base Nacional Comum Curricular e Base Técnica. Dessa forma, o NPO possui duas coordenações: uma central, sob a responsabilidade da Coordenação de Inovação, e as locais, exercida pelos coordenadores vinculados ao Núcleo em cada escola.

A Coordenação de Inovação, como principal órgão de gestão do NPO é responsável por:

- Implementar programas de pesquisa no âmbito dos Centros Educa Mais;

- Promover e supervisionar a divulgação, junto às comunidades interna e externa, dos resultados obtidos pelas pesquisas desenvolvidas nos Centros;

- Coordenar a participação de professores, envolvendo intercâmbio e/ou cooperação técnica entre instituições congêneres;

- Apoiar a formação de grupos de estudos e pesquisas nos Centros Educa Mais, objetivando o desenvolvimento de projetos de pesquisa de interesse institucional e social;

- Incentivar a participação de docentes e estudantes em encontros, congressos e seminários, contribuindo para o processo permanente de desenvolvimento técnico-científico da comunidade escolar dos Centros Educa Mais;

- Desenvolver mecanismos de apoio, acompanhamento e controle dos programas e projetos de Pesquisa, tendo como diretrizes o respeito às características regionais e a relevância dos resultados;

- Implementar e promover ações de orientações para os discentes e docentes, no processo de buscas e consultas a bancos e bases de dados nacionais e internacionais de interesse institucional e formações continuadas;

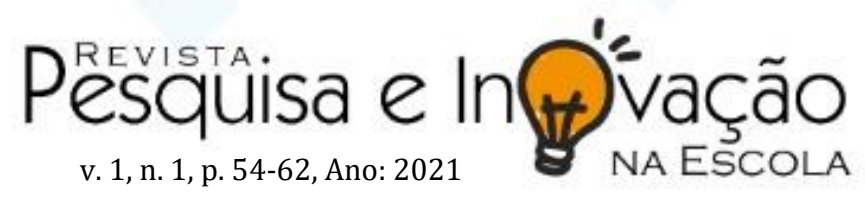


- Elaborar o Calendário de Olimpíadas do Conhecimento, com base no cronograma de cada Olimpíada.

Conforme mencionado acima, no âmbito escolar, o Núcleo de Pesquisa e Olimpíadas (NPO) possui professores coordenadores (as) do quadro docente do Centro Educa Mais em que está lotado, que compõem a Coordenação Local do NPO, que é orientada e supervisionada pela Coordenação de Inovação (Coordenação Central), em anuência com a Gestão Pedagógica da escola. Cabe à Coordenação Local:

- Implementar as atividades do Núcleo de acordo com as áreas do conhecimento da Base Nacional Comum Curricular e Parte Diversificada;

- Elaborar cronograma interno de atividades para o Núcleo;

- Incentivar professores e estudantes a submeterem projetos de pesquisa a órgãos de fomento estaduais, nacionais e internacionais e a participarem das Olimpíadas do Conhecimento;

- Organizar e disponibilizar informações à Coordenação Central do NPO acerca de projetos e pesquisas;

- Sistematizar e disponibilizar informações à Coordenação de Inovação acerca das participações do Centro Educa Mais nas Olimpíadas do Conhecimento;

- Promover o intercâmbio científico e técnico entre professores e estudantes a partir de parcerias interinstitucionais;

- Agir como elo no processo de socialização das informações no âmbito do Centros Educa Mais ao qual está lotado junto à Coordenação de Inovação;

- Coordenar e apoiar eventos científicos e olimpíadas de conhecimento.

O processo de implantação do NPO tem ocorrido de forma gradativa, levando em consideração o contexto escolar de cada Centro Educa Mais. Entretanto, ações assertivas são realizadas para padronizar as atividades, de forma institucional e pedagógica. Dentre elas, podemos elencar:

- Oferta de formações continuadas em Pesquisa e Inovação aos Coordenadores Locais do NPO;

- Suporte à implementação de iniciação científica nas escolas;

- Suporte aos projetos desenvolvidos pela Parte Diversificada (eletivas, estudo orientado e projeto de vida);

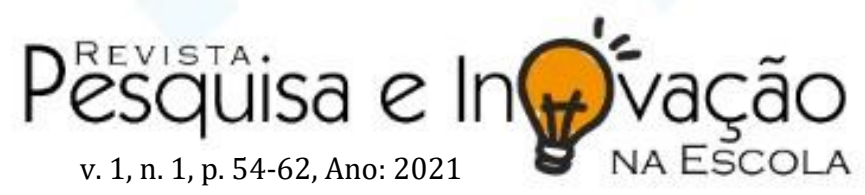


- Compartilhamento de informações e conhecimentos adquiridos nas formações continuadas aos demais professores dos Centros Educa Mais.

Para acompanhamento das atividades das Coordenações Locais, a Coordenação de Inovação encaminha quinzenalmente formulário na plataforma Google Forms, informando a quantidade de alunos inscritos em olimpíadas por ano. Além disso, é solicitado um relatório de atividade após o término da olimpíada na qual a escola concorreu.

Embora o Núcleo de Pesquisa e Olimpíadas tenha sido implantado em 2021, o incentivo a professores e alunos para participarem de Olimpíadas do Conhecimento e eventos científicos, bem como o levantamento de dados de participação e premiação ocorre desde o ano de 2019. Dessa forma, os dados apresentados a seguir são oriundos deste levantamento, que se deu através de relatórios enviados pelos gestores escolares (antes da implantação do NPO) e pelos professores coordenadores. Foi considerado como indicador de participação o número de alunos que efetivamente participaram das olimpíadas e eventos, e não apenas o número de alunos inscritos.

\section{RESULTADOS E DISCUSSÃO}

Embora que nos anos anteriores os Centros Educa Mais tenham apresentado um quantitativo elevado de participação em olimpíadas e eventos científicos; em 2021, após a implantação do NPO, houve um aumento expressivo nesse indicador (Figura 1). Em 2020, os valores foram baixos, quando comparado com os outros dois anos considerados neste relato, devido à pandemia de COVID-19, que levou muitos eventos a suspenderem seus cronogramas e se adaptarem para um formato remoto em 2021.

Ao todo, os Centros Educa Mais obtiveram 458 premiações entre o ano de 2019 e 2021, dentre medalhas de ouro, prata, bronze e menções honrosas. Destas, a maior quantidade se concentrou no ano de 2021 (Figura 1). Destaca-se que este levantamento considera apenas os dados obtidos até o mês de junho de 2021, e ainda assim, o quantitativo supera o somatório de premiações nos dois anos anteriores. 
Figura 1: Quantitativo da participação e premiação dos estudantes e professores dos Centros Educa Mais em Olimpíadas do Conhecimento e eventos científicos entre os anos de 2019 e 2021.

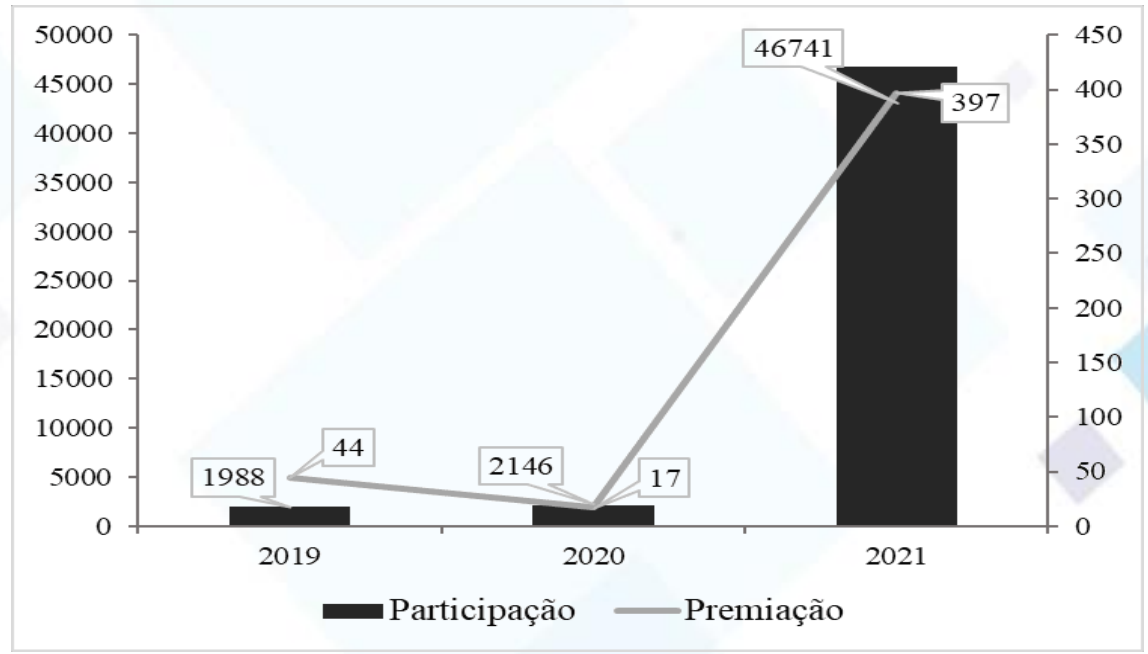

Embora exista um grande temor na participação em Olimpíadas de Conhecimento por parte de muitos educadores, os impactos positivos desta metodologia no processo de ensinoaprendizagem são fortemente reconhecidos (JAFELICE, 2005). Por outro lado, observa-se com mais frequência que muitos educadores têm estimulado a participação dos alunos em atividades científicas extracurriculares, como um caminho para os alunos desenvolverem suas habilidades e interesse pela ciência (MANN, 1984; GROTE, 1995).

Estimular os estudantes a participarem de atividades científicas pode ser muito importante a longo prazo, principalmente para a escolha da carreira (PEREIRA; MAREGA JR, 2009). No contexto escolar, a participação em olimpíadas e eventos em busca de premiações pode motivar os alunos durante as aulas, bem como a realizarem exercícios, revisarem conteúdos e buscarem gradativamente compreender tudo o que foi ensinado. Afinal, essas competições tratam de problemas que requerem do estudante imaginação e raciocínio, e não só os conhecimentos prévios e pré-estabelecidos (ALVES; SANTOS, 2017).

Nesse sentido, observa-se que os eventos científicos, em especial as Olimpíadas do Conhecimento, propõem, de forma satisfatória o desenvolvimento do pensar produtivo do aluno e de forma análoga o desenvolvimento de seu raciocínio, atenuando-se no constante interesse e desafio do professor em tornar as aulas mais dinâmicas, fornecendo base, estratégias para a solução de tais problemas e preparando-os para novas situações de maneira criativa (DANTE, 2010).

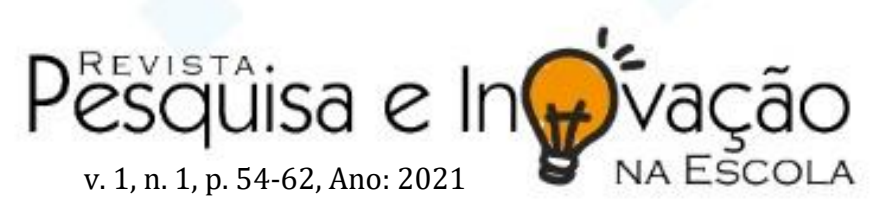




\section{CONSIDERAÇÕES FINAIS}

O levantamento de participação e premiações em eventos e olimpíadas indicam que o Núcleo de Pesquisa s e Olimpíadas (NPO), teve importante papel nos resultados alcançados, haja vista que após sua implementação, os resultados aumentaram de forma representativa. Assim, a implementação de um grupo executivo especifico para viabilizar a Ciência dentro da escola, se mostra uma excelente estratégia para a promoção da Educação Científica, além de trazer visibilidade para a escola, principalmente tendo em vista as mudanças curriculares propostas pelo Novo Ensino Médio, onde a investigação dentro da escola é tema prioritário.

\section{REFERÊNCIAS}

BRASIL. Lei $\mathbf{n}^{\mathbf{0}}$ 13.005, de 25 de junho de 2014. Aprova o Plano Nacional de Educação PNE e dá outras providências. Diário Oficial da União, Brasília, DF, 2014.

DANTE, L. R. Formulação e Resolução de Problemas de Matemática: Teoria e prática. São Paulo. Editora Ática. 2010.

CHASSOT, A. Alfabetização científica: uma possibilidade para a inclusão social. Revista brasileira de educação, p. 89-100, 2003.

FÓRUM DE REFLEXÃO UNIVERSITÁRIA. Desafios da pesquisa no Brasil: uma contribuição ao debate. São Paulo em Perspectiva, v. 16, n. 4, p. 15-23, 2002.

GROTE, M. G. Science teacher educators' opinions about science projects and science fairs. Journal of Science Teacher Education, v. 6, p. 48-52, 1995.

JAFELICE, L. C. Não, às olimpíadas de astronomia. sim, a iniciativas puramente cooperativas. In: Reunião Anual da Sociedade Astronômica Brasileira. Águas de Lindóia: SAB, 2005. v. 25, p. 89. Painel 36.

MANN, J. Z. Science day guide. Columbus: Ohio Academy of Science. 1984.

MARANHÃO. Lei no 10.099, de 11 de junho de 2014. Aprova o Plano Estadual de Educação do Estado do Maranhão e dá outras providências, 2014.

MARANHÃO. Lei no 10.995 de 11 de março de 2019. Institui a Política Educacional "Escola Digna", e dá outras providências, 2019.

MARANHÃO. Diretrizes operacionais 2021: IEMA e Centros Educa Mais. Secretaria de Estado da Educação, 2021.

PEREIRA, R. G.; MAREGA JR, E. A Olimpíada brasileira de física no estado de São Paulo e a difusão do conhecimento na Universidade de São Paulo. Revista de Cultura e Extensão USP, v. 1, p. 37-42, 2009.

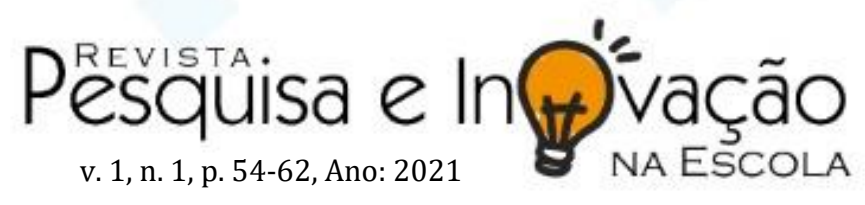


PETRUCCI, D.; URE, M. C. D. Imagen de la ciencia en alumnos universitarios: una revisión y resultados. Enseñanza de las ciencias: revista de investigación y experiencias didácticas, p. 217-229, 2001.

SANTOS, A. P. R. A.; ALVES, F. R. V. A teoria das situações didáticas no ensino das Olimpíadas de Matemática: Uma aplicação do Teorema de Pitot. Indagatio Didactica, v. 9, n. 4, p. 279-296, 2017. 